\title{
Applications of Unmanned Aerial Vehicles in Geosciences: Introduction
}

\section{TOMASZ NIEDZIELSKI ${ }^{1}$}

In the last decade, unmanned aerial vehicles (UAVs)—informally known as drones-became standard tools for acquiring spatial data to support various geoscientific analyses. Although the most common applications of drones are associated with acquiring aerial images and processing them using photogrammetric methods to make maps, the miniaturization of geophysical instruments has recently opened new opportunities to install them on-board drones (Hatch 2017). Modern UAVs have longer endurance than their predecessors and therefore heavier payload, like geophysical sensors, can be hung under drones. Geophysicists make use of dronebased mapping (e.g., Bemis et al. 2014) as well as employ various UAV-mounted geophysical sensors (Hatch 2017). Nowadays, drones enable the measurements of the Earth's subsurface and allow geoscientists to observe its surface, the hydrosphere or the troposphere.

The most common geoscientific application of UAVs uses aerial imagery to reconstruct the Earth's elevations through producing digital surface models and to reconstruct land cover through generating orthophotos. The two products are produced by the Structure-from-Motion (SfM) algorithm (Westoby et al. 2012) which generates sparse and dense point clouds on a basis of visible-light or near-infrared aerial images. The increase in the quality of georeferencing, achieved mainly through the use of ground control points and real-time kinematic technology, led to the reproducibility and repeatability of multitemporal spatial data (Clapuyt et al. 2016). As a

1 Department of Geoinformatics and Cartography, Faculty of Earth Sciences and Environmental Management, University of Wrocław, pl. Uniwersytecki 1, 50-137 Wrocław, Poland. E-mail: tomasz.niedzielski@uwr.edu.pl consequence, the UAV-based multi-temporal digital surface models and orthophotos became suitable for detecting changes in the Earth's surface. These UAVbased maps can be used as base maps, as noticed by an environmental geophysicist (Hatch 2016).

Not only digital cameras but also more advanced geophysical sensors are also mounted on-board drones. Underground survey can be carried out, for instance, by UAV-borne ground penetrating radar (Chandra and Tanzi 2018) or drone-mounted magnetometers (Versteeg et al. 2007). Underwater survey may be conducted using UAVs equipped with the light detection and ranging (LIDAR) sensor, with laser pulses in green domain of the spectrum (Mandlburger et al. 2016). The Earth's surface may also be monitored by standard LIDAR (Lin et al. 2011) or multispectral cameras (Ahmed et al. 2017). Observations of the troposphere are conducted using dedicated meteorological sensors mounted on-board drones (Spiess et al. 2007) or utilizing standard UAV equipment such as the Pitot tubes and the Global Navigation Satellite System receivers (Niedzielski et al. 2017).

The variety of UAV applications-covering the investigations into the Earth's subsurface, its surface, the hydrosphere and the troposphere-were discussed during the 23rd Cartographic School "Applications of unmanned aerial vehicles in geosciences" which took place in Świeradów-Zdrój (Poland) on 8-10 June 2016. In the aftermath of the conference and the associated workshop, its participants and other researchers contributed to this topical issue of Pure and Applied Geophysics.

Cunningham et al. (2018) carried out a demonstration UAV survey of zinc deposits in Nash Creek, New Brunswick, Canada. They approached the problem from a geophysical perspective and utilized a cesium vapor magnetometer mounted on-board a 
UAV. The paper contributes to our understanding of potentials and limitations of UAV-based magnetic survey, especially with respect to well-established ground survey and manned aircraft survey. Yet another UAV-supported analysis of underground activity was presented by Schultz-Fellenz et al. (2018). The authors investigated the influence of controlled underground chemical explosion in granite on uplift, subsidence, surface fractures and morphological change. The SfM-based pre- and post-shot digital surface models allowed the authors to quantify surface changes of the physical terrain. The authors claimed that the SfM-based methodology "provides valuable data to link with other geological and geophysical techniques".

Change detection based on UAV digital surface models can be a very difficult problem when the physical terrain is highly dynamic and unstable. Such difficulties occur while investigating aeolian environments such as, for instance, sand dunes. Česnulevičius et al. (2018) attempted to utilize the SfM method for dune mapping and inferring its dynamics. Based on the analysis of data collected in the Curonian Spit, they formulated a few recommendations about the usability of UAVs for monitoring aeolian environments. The problem of surface stability does not occur on rock outcrops as presented by Kasprzak et al. (2018). They carried out a feasibility study about the use of the SfM method for mapping granite tors, on the example of Starościńskie Skały in the Sudetes in southwestern Poland. They concluded that the approach enables the identification of rock micro-topography, including complex joint systems, weathering pits, rills and karrens. The SfM method can therefore complement indirect geophysical measurements of rock joint geometry. Visualization of Earth's topography is an important element of the inference on its changes. Halik and Smaczyński (2018) integrated the virtual reality technology with UAV-based digital surface models, and visualized the natural aggregate mine in western Poland. For many years, virtual reality has been perceived as an added value in exploration geophysics (Midttun et al. 2000), and thus its integration with the UAV-based digital surface models may be used to support geophysical surveying of the physical terrain.
The UAV-supported determination of the dynamics of fluvial forms, which impact hydrological processes, may enhance or validate results obtained using hydrogeophysical methods. Langhammer and Vacková (2018) investigated fluvial landforms that are formed or modified by flooding. The authors studied the specific snow-melt flood episode that occurred in December 2015 in the Šumava Mountains in Czechia. Riverine morphology was also the topic of the paper by Dimitriou and Stavroulaki (2018) who used SfM to determine spatial and temporal patterns of erosion and deposition in the Spercheios river basin in Greece. Another water-related problem was tackled by Templin et al. (2018) who conducted a detailed fieldwork in the Suskie Lake in northern Poland, and determined its shoreline using a UAV survey.

Also, UAVs contributed to geophysics of snow. Niedzielski et al. (2018) utilized the UAV-based orthophotos from study sites located in the Izerskie Mountains in southwestern Poland to estimate snow extent. The k-means classification was applied to discriminate between snow-free and snow-covered terrain. Adams et al. (2018) addressed the issue of accuracy and precision of snow depth reconstructions using SfM, with a particular emphasis put on the slope scale. They carried out the field experiment in the Tuxer Alps in Austria.

Meteorological applications of UAVs go beyond spatial survey of terrain and include the production of vertical profiles of the atmosphere. Chiliński et al. (2018) carried out a case study of atmospheric aerosols at two stations (Świder and Warsaw) located in Poland. They utilized a UAV with microaethalometer and radiosonde on-board, and offered a concept of sounding atmospheric aerosols using UAVs. Atmospheric phenomena, such as for instance clouds, usually influence remote sensing data. Niedzielski and Jurecka (2018) carried out a field experiment in the Izerskie Mountains in southwestern Poland, the aim of which was to automatically detect persons in photographs taken by a UAV operating in the bottom of low-altitude clouds. They argued that there exists a certain level of intermediate clouddriven image blurriness for which the performance of the search algorithm increases. 
The majority of the described studies made use of micro UAVs, carrying limited payload. Rarely, geoscientists utilize mini UAVs, with maximum take-off weight up to a few tens of kilograms, with a considerable payload capacity. One of such examples was presented in the technical report by Kaňuk et al. (2018) who used an unmanned helicopter with onboard LIDAR and camera or on-board hyperspectral pushbroom scanner, the sensors which are also dedicated to carry out geophysical measurements. This topical issue ends up with a historical view of drones. Kolejka and Plánka (2018) offered the technical report on the development of UAVs in former Czechoslovakia, beginning their story in mid-1960s. They published photographs of first remotely controlled aircrafts in that country and published historical aerial data collected by visible-light and multispectral cameras mounted on UAVs.

This topical issue highlights recent advances in UAV applications in geosciences, including the use of various on-board cameras and sensors as well as data processing methods. Since the volume is a selection of case studies carried out with the use of UAVs, it may be interesting to scientists and, predominantly, to students and practitioners who will be provided with the materials to follow real-world examples of the UAV applications in Earth sciences. The case studies cover a wide range of problems solved with the support offered by drones, including the monitoring of surface and subsurface of terrain as well as the investigations into phenomena acting in the hydrosphere and the troposphere.

\section{Acknowledgements}

The Guest Editor would like to thank Dr Renata Dmowska, the Editor-in-Chief for topical issues and book reviews of Pure and Applied Geophysics, for offering valuable support during the editorial work. Special thanks should also go to all reviewers who read the manuscripts and offered valuable remarks. Last but not least, Dr Ismail Gultepe and Prof. Andrzej Icha are acknowledged for handling Guest Editor's manuscripts.
Open Access This article is distributed under the terms of the Creative Commons Attribution 4.0 International License (http:// creativecommons.org/licenses/by/4.0/), which permits unrestricted use, distribution, and reproduction in any medium, provided you give appropriate credit to the original author(s) and the source, provide a link to the Creative Commons license, and indicate if changes were made.

\section{REFERENCES}

Adams, M. S., Bühler, Y., \& Fromm, R. (2018). Multitemporal accuracy and precision assessment of unmanned aerial system photogrammetry for slope-scale snow depth maps in alpine terrain. Pure and Applied Geophysics. https://doi.org/10.1007/ s00024-017-1748-y.

Ahmed, O. S., Shemrock, A., Chabot, D., Dillon, C., Williams, G., Wasson, R., et al. (2017). Hierarchical land cover and vegetation classification using multispectral data acquired from an unmanned aerial vehicle. International Journal of Remote Sensing, 38, 2037-2052.

Bemis, S. P., Micklethwaite, S., Turner, D., James, M. R., Akciz, S., Thiele, S. T., et al. (2014). Ground-based and UAV-based photogrammetry: A multi-scale, high-resolution mapping tool for structural geology and paleoseismology. Journal of Structural Geology, 69A, 163-178.

Česnulevičius, A., Bautrènas, A., Bevainis, L., Ovodas, D., \& Papšys, K. (2018). Applicability of unmanned aerial vehicles in research on aeolian processes. Pure and Applied Geophysics. https://doi.org/10.1007/s00024-018-1785-1.

Chandra, M., \& Tanzi, T. J. (2018). Drone-borne GPR design: Propagation issues. Comptes Rendus Physique, 19, 72-84.

Chiliński, M. T., Markowicz, K. M., \& Kubicki, M. (2018). UAS as a support for atmospheric aerosols research: Case study. Pure and Applied Geophysics. https://doi.org/10.1007/s00024-0181767-3.

Clapuyt, F., Vanacker, V., \& Van Oost, K. (2016). Reproducibility of UAV-based earth topography reconstructions based on structure-from-motion algorithms. Geomorphology, 260, 4-15.

Cunningham, M., Samson, C., Wood, A., \& Cook, I. (2018). Aeromagnetic surveying with a rotary-wing unmanned aircraft system: A case study from a zinc deposit in Nash Creek, New Brunswick, Canada. Pure and Applied Geophysics. https://doi. org/10.1007/s00024-017-1736-2.

Dimitriou, E., \& Stavroulaki, E. (2018). Assessment of riverine morphology and habitat regime using unmanned aerial vehicles in a Mediterranean environment. Pure and Applied Geophysics. https://doi.org/10.1007/s00024-018-1929-3.

Halik, Ł., \& Smaczyński, M. (2018). Geovisualisation of relief in a virtual reality system on the basis of low-level aerial imagery. Pure and Applied Geophysics. https://doi.org/10.1007/s00024017-1755-z.

Hatch, M. (2016). Environmental geophysics: Using drones to create base maps. Preview, 185, 31-32.

Hatch, M. (2017). Environmental geophysics: Developments in miniaturisation technology. Preview, 189, 32-33.

Kaňuk, J., Gallay, M., Eck, C., Zgraggen, C., \& Dvorný, E. (2018). Technical report: Unmanned helicopter solution for survey-grade 
lidar and hyperspectral mapping. Pure and Applied Geophysics. https://doi.org/10.1007/s00024-018-1873-2.

Kasprzak, M., Jancewicz, K., \& Michniewicz, A. (2018). UAV and SfM in detailed geomorphological mapping of granite tors: An example of Starościńskie Skały (Sudetes, SW Poland). Pure and Applied Geophysics. https://doi.org/10.1007/s00024-017-1730-8.

Kolejka, J., \& Plánka, L. (2018). Technical report: The development and experience with UAV research applications in former Czechoslovakia (1960s-1990s). Pure and Applied Geophysics. https://doi.org/10.1007/s00024-018-1807-z.

Langhammer, J., \& Vacková, T. (2018). Detection and mapping of the geomorphic effects of flooding using UAV photogrammetry. Pure and Applied Geophysics. https://doi.org/10.1007/s00024018-1874-1.

Lin, Y., Hyyppa, J., \& Jaakkola, A. (2011). Mini-UAV-borne LIDAR for fine-scale mapping. IEEE Geoscience and Remote Sensing Letters, 8, 426-430.

Mandlburger, G., Pfennigbauer, M., Wieser, M., Riegl, U., \& Pfeifer, N. (2016). Evaluation of a novel UAV-borne topobathymetric laser profiler. The International Archives of Photogrammetry, Remote Sensing and Spatial Information Sciences, 41, 933.

Midttun, M., Helland, R., \& Finnstrom, E. (2000). Virtual realityadding value to exploration and production. The Leading Edge, 19, 538-544.

Niedzielski, T., \& Jurecka, M. (2018). Can clouds improve the performance of automated human detection in aerial images? Pure and Applied Geophysics. https://doi.org/10.1007/s00024018-1931-9.
Niedzielski, T., Skjøth, C., Werner, M., Spallek, W., Witek, M., Sawiński, T., et al. (2017). Are estimates of wind characteristics based on measurements with Pitot tubes and GNSS receivers mounted on consumer-grade unmanned aerial vehicles applicable in meteorological studies? Environmental Monitoring and Assessment, 189, 431.

Niedzielski, T., Spallek, W., \& Witek-Kasprzak, M. (2018). Automated snow extent mapping based on orthophoto images from unmanned aerial vehicles. Pure and Applied Geophysics. https://doi.org/10.1007/s00024-018-1843-8.

Schultz-Fellenz, E. S., Coppersmith, R. T., Sussman, A. J., Swanson, E. M., \& Cooley, J. A. (2018). Detecting surface changes from an underground explosion in granite using unmanned aerial system photogrammetry. Pure and Applied Geophysics. https://doi.org/10.1007/s00024-017-1649-0.

Spiess, T., Bange, J., Buschmann, M., \& Vörsmann, P. (2007). First application of the meteorological Mini-UAV 'M2AV'. Meteorologische Zeitschrift, 16, 159-169.

Templin, T., Popielarczyk, D., \& Kosecki, R. (2018). Application of low-cost fixed-wing UAV for inland lakes shoreline investigation. Pure and Applied Geophysics. https://doi.org/10.1007/ s00024-017-1707-7.

Versteeg, R., McKay, M., Anderson, M., Johnson, R., Selfridge, B., \& Bennett, J. (2007). Feasibility study for an autonomous UAVmagnetometer system (No. INL/EXT-07-13386). Idaho Falls: Idaho National Lab.

Westoby, M. J., Brasington, J., Glasser, N. F., Hambrey, M. J., \& Reynolds, J. M. (2012). 'Structure-from-Motion' photogrammetry: A low-cost, effective tool for geoscience applications. Geomorphology, 179, 300-314 